\title{
FUNDAMENTOS DE ELETROFISIOLOGIA: POTENCIAIS DE MEMBRANA
}

\author{
ELETROPHYSIOLOGY FUNDAMENTALS: MEMBRANE POTENTIALS
}

\author{
Edson Delattre
}

Docente. Departamento de Fisiologia e Biofísica. Instituto de Biologia - UNICAMP

CoRRespondência: Edson Delattre - Departamento de Fisiologia e Biofísica do Instituto de Biologia da Universidade Estadual de Campinas - Cidade Universitária Zeferino Vaz - Barão Geraldo - CEP 13 083-970 - Fax: (19) 37886185 - e-mail: delattre@unicamp.br

Delattre E. Fundamentos de eletrofisiologia: potenciais de membrana. Medicina (Ribeirão Preto) 2007; 40 (3): 378-93, jul./set.

RESUMO: A eletrofisiologia é de fundamental importância para os profissionais da área médica, não obstante seja um dos temas de difícil compreensão pelos estudantes. Com base em nossa experiência didático-pedagógica, sentimos a necessidade de auxiliar o estudante que se inicia nesse assunto, ou que o retoma. Assim, elaboramos um instrumento auto-instrucional de ensino-aprendizagem, de fácil utilização, onde o domínio seqüencial dos conteúdos favorece as novas aquisições cognitivas. $O$ instrumento visa tratar dos princípios físico-químicos da bioeletrogênese, fornecendo a base de estudo da neurofisiologia, da endocrinologia e da eletrofisiologia cardíaca inter alia. Precedido de uma introdução teórica e dos objetivos, apresenta uma seqüência lógica, articulada e hierarquizada de setenta questões objetivas de múltipla escolha, com três alternativas, sendo cinqüenta e nove questões básicas e onze aplicadas. As questões objetivam estimular o estudante a descobrir, por meio do raciocínio lógico-dedutivo, os fundamentos bioelétricos da geração e manutenção do potencial de membrana. Em paralelo com o conteúdo das proposições, foram dispostos vários insets reforçadores dos conceitos essenciais ou que destacam aspectos relevantes e aplicados do tema. $\mathrm{Na}$ parte final, apresentou-se o gabarito das questões. O instrumento foi utilizado em atividades de estudo em grupos, de alunos de cursos da área biológica, com resultados satisfatórios.

Descritores: Potenciais da Membrana. Eletrofisiologia. Biofísica. Ensino. Aprendizagem. Instrução Programada.

\section{1- INTRODUÇÃO}

Um importante objetivo de ensino da fisiologia é prover os estudantes com uma sólida compreensão dos conceitos básicos que fundamentam os processos vitais de ordem superior, aumentando sua percepção dos conceitos unificadores (v.g. a dependência que os sistemas vivos têm das leis físico-químicas) e melhorando suas habilidades em resolver problemas ${ }^{1}$.

O estudo da fisiologia das membranas excitáveis é de grande importância nas disciplinas de Neu- rociências e de Fisiologia, nos cursos de graduação da área médica ${ }^{2}$. Seria difícil exagerar o significado fisiológico da diferença de potencial elétrico transmembranar $^{3}$. Entretanto, a relevância do estudo da atividade elétrica dos seres vivos não se restringe ao seu caráter acadêmico, voltado apenas para o conhecimento e a interpretação das leis que regem o funcionamento dos seres vivos. Várias aplicações de caráter prático, principalmente na área médica, podem ser enumeradas, tais como: a eletrocardiografia, a eletroencefalografia e a eletromiografia ${ }^{4}$. 
A análise dos fenômenos bioelétricos se constitui, muitas vezes, em importante ferramenta de estudo dos fenômenos fisiológicos. Longe de ser um problema de ciência pura, o estudo da bioeletrogênese é de singular importância e atualidade para o fisiologista, o biofísico e, particularmente, o médico ${ }^{4}$. Em razão do amplo papel do potencial de membrana nos processos fisiológicos e da elevada fração do suprimento energético dispendido na manutenção do potencial de membrana, é essencial que os estudantes iniciantes de fisiologia tenham um bom entendimento de como os potenciais de membrana são gerados ${ }^{5}$.

No processo de ensino-aprendizagem de Fisiologia e Biofísica, em cursos de graduação, detectamos, freqüentemente, grande dificuldade na compreensão de conteúdos da eletrofisiologia básica. Um dos aspectos centrais dessa dificuldade fica evidente quando se discutem as conseqüências, para o potencial de membrana, do aumento da concentração extracelular de um sal de potássio. Possivelmente, este é o aspecto central deste instrumento de estudo, mormente quando se sabe que diversas condições fisiopatológicas apresentam, como um dos distúrbios homeostáticos, alterações da concentração de potássio nos líquidos extracelulares ( $v . g$. insuficiência renal crônica; diabetes; lesões musculares inter alia). Em concordância, diversos autores destacam que a noção de potencial de repouso da membrana plasmática é um dos mais difíceis conceitos fisiológicos que os estudantes precisam dominar, sujeitando os alunos a vários malentendidos $^{6 / 9}$. Por essas razões, é crítico que todos os estudantes de fisiologia tenham uma clara compreensão das bases físico-químicas do potencial de repouso das membranas ${ }^{3}$.

A aplicação de uma questão representativa desse assunto, a estudantes que já haviam cursado um semestre de Neurofisiologia, demonstrou que parte dos estudantes, aparentemente: (a) desconheciam a forma de distribuição de íons, entre o extra e o intracelular; (b) confundiam concentração de equilíbrio com potencial de equilíbrio; (c) não entendiam o princípio da neutralidade elétrica; (d) confundiam os sentidos de variação do potencial: potencial aumentado/diminuído e potencial mais positivo/mais negativo; (d) foram incapazes de explicar o conceito de potencial de equilíbrio eletroquímico de um íon ${ }^{8}$.

Esses dados, portanto, reforçam nossas observações. Assim, sentimos a necessidade de auxiliar o estudante que se inicia nesse assunto, ou que o retoma. A forma apresentada é um instrumento auto- instrucional de ensino-aprendizagem, de fácil utilização, onde o domínio seqüencial dos conteúdos serve de suporte às novas aquisições cognitivas. $\mathrm{O}$ instrumento foi elaborado, aplicado e aperfeiçoado, nos últimos anos, tendo sido utilizado em atividades de estudo em grupos, por alunos de cursos da área biológica, com resultados satisfatórios.

\section{1- Conceitos básicos e suas aplicações}

Grande número de fenômenos biológicos importantes é acompanhado de manifestações elétricas celulares. Em repouso, as células vivas apresentam diferença de potencial elétrico de várias dezenas de milivolts através da membrana plasmática, com o meio intracelular negativo em relação aos líquidos extracelulares (LEC). A gênese desse potencial de membrana está associada a mecanismos de transporte de íons, que criam um meio iônico intracelular de composição distinta daquela do meio iônico extracelular. Nesse particular, os processos de difusão (potenciais de difusão) e os transportes ativos (potenciais de bombas eletrogênicas) representam os mecanismos básicos responsáveis pela polarização da membrana plasmática. A difusão de íons a favor de gradientes de concentração é a mais importante causa de manifestação elétrica em sistemas biológicos ${ }^{4}$.

Uma notável característica de todas as células vivas é a diferença de potencial existente entre os fluidos intra e extracelulares. Essa diferença de potencial usualmente varia entre 10 e $100 \mathrm{mV}$, com o interior da célula sendo eletronegativo em relação ao exterior ${ }^{10}$.

O potencial de membrana está implicado em inúmeros processos celulares, tais como: (a) transportes iônicos e, conseqüentemente, de água através das membranas celulares e entre compartimentos orgânicos; (b) transporte de numerosos nutrientes, para dentro e para fora das células; (c) transporte de nutrientes acoplados ao sódio, nos enterócitos; (d) secreção de cloreto, por epitélios; (e) sinalização celular; (f) sinalização elétrica nas células excitáveis; (g) geração de potencial de ação pós-sináptico; (h) função cerebral, incluindo-se os processos cognitivos; (i) percepção sensorial; (j) contração muscular; (l) secreção hormonal e (m) proliferação e ciclo celular ${ }^{3,5}$.

Os três principais íons $\left(\mathrm{K}^{+}, \mathrm{Na}^{+}\right.$e $\left.\mathrm{Cl}^{-}\right)$participantes da geração do potencial de membrana, nas células em geral, também desempenham outras importantes ações em múltiplas células, em tecidos e órgãos humanos. Nas fibras nervosas e nas células musculares a relação entre o potássio intra e extracelular de- 
termina a excitabilidade neuromuscular. Alguns estudos demonstraram uma associação positiva entre dietas ricas em potássio e o controle da pressão arterial, assim como a prevenção de acidentes vasculares cerebrais ${ }^{11}$. Igualmente, o potássio está implicado na atividade marca-passo cardíaca e na fisiologia de músculos lisos, bem como é fundamental para a homeostase glicêmica. O potássio exerce ações hepáticas e integra uma alça de retroalimentação negativa, que controla a secreção pancreática de insulina, bem como a atividade da bomba de $\mathrm{Na}^{+} / \mathrm{K}^{+}$ATPase, nas células em geral. Por outro lado, também atua na síntese protéica e participa de reações enzimáticas ${ }^{12}$. Alterações no gradiente de potássio, tipicamente resultantes de mudanças no potássio extracelular, podem ser extremamente importantes, tanto fisiologicamente, quanto clinicamente ${ }^{3}$.

O sódio é fundamental no controle da osmoticidade, além de participar na geração da atividade elétrica em diferentes tecidos excitáveis. Já o cloreto é bombeado ativamente para compor o suco gástrico, além de participar, tanto do controle da pressão osmótica dos líquidos extracelulares, quanto da pressão arterial.

Os íons fluem através das membranas, em grande parte, percorrendo diferentes canais. Os canais iônicos estão presentes nos seres vivos, de bactérias até mamíferos. São responsáveis pela transmissão elétrica em todo o sistema nervoso e participam de inúmeros processos fisiológicos e bioquímicos, como contração muscular, secreção de neurotransmissores e hormônios, dentre muitos outros ${ }^{13}$.

A utilização de novas técnicas e ferramentas avançadas de Biofísica, Eletrofisiologia e Biologia Molecular permitiu que se conhecesse a estrutura e o funcionamento dos canais iônicos, base molecular e fundamental para a ocorrência dos fenômenos eletrofisiológicos. Não obstante, o conhecimento da essência dos fenômenos elétricos nos seres vivos depende do entendimento de processos e conceitos básicos, tais como: potenciais de difusão; equilíbrio eletroquímico; potenciais de equilíbrio eletroquímico e potenciais de membrana, além dos potenciais de ação, não tratados neste estudo.

\section{2- OBJETIVO GERAL}

Enfocar os princípios físico-químicos da Eletrofisiologia, fornecendo a base para se estudar a neurofisiologia, a atividade elétrica das células endócrinas e dos músculos lisos e estriados, a eletrofisiologia cardíaca e a função tubular renal, dentre outras aplicações.

Obviamente, não se pretende abranger todo o assunto, mas sim fornecer os fundamentos indispensáveis à continuidade desse estudo.

\section{3- OBJETIVOS OPERACIONAIS}

Ao final do estudo, o usuário será capaz de:

a) Esquematizar e explicar a geração de potenciais de difusão.

b) Esquematizar e explicar o desenvolvimento, a manutenção e o significado conceitual do equilíbrio eletroquímico de um íon.

c) Esquematizar e explicar o surgimento e a manutenção de um potencial de equilíbrio eletroquímico de umíon.

d) Explicar o princípio da eletroneutralidade nas células, na geração de potenciais elétricos.

e) Utilizando as figuras deste estudo, explicar de que forma alterações das concentrações iônicas, intra e extracelulares de potássio, sódio e cloreto interferem no potencial de equilíbrio eletroquímico de cada íon.

f) Aplicar a equação de Nernst e explicar o seu significado prático.

g) Aplicando a equação de Nernst, explicar as alterações do potencial de membrana após aumento ou redução das concentrações iônicas, nos líquidos extra e intracelulares.

h) Aplicar a equação do campo constante de Goldman, Hodgkin e Katz (equação de Goldman), no cálculo de potenciais de membrana.

i) Aplicando as equações de Nernst e de Goldman, determinar os efeitos de alterações da temperatura nos potenciais de equilíbrio eletroquímico de íons, bem como nos potencias de membrana.

j) Explicar a razão das diferenças de valores dos potenciais de membrana, em diferentes células.

1) Explicar por que o potencial de membrana de astrócitos apresenta valor igual àquele do potencial de equilíbrio eletroquímico do potássio.

m) Explicar por que o potencial de membrana de neurônios e células musculares apresenta valor próximo àquele do potencial de equilíbrio eletroquímico do potássio.

n) Explicar por que o potencial de membrana das células em geral apresenta valor igual àquele do potencial de equilíbrio eletroquímico do íon cloreto. 
o) Explicar, com base nos gradientes químicos de potássio, por que as alterações de concentração desse cátion, nos líquidos extra e intracelulares, provocam mudanças no potencial de membrana.

p) Calcular os valores do potencial de membrana, simulando alterações das concentrações do potássio.

q) Simulando alterações da permeabilidade da membrana aos íons sódio e potássio, calcular os potenciais de membrana resultantes.

r) Explicar por que o potencial de membrana é um potencial dissipativo, ao contrário dos potenciais de equilíbrio eletroquímico.

s) Justificar a importância dos gradientes iônicos através da membrana plasmática, para a homeostase celular e orgânica.

t) Explicar a atuação da bomba de $\mathrm{Na}^{+} / \mathrm{K}^{+}$ATPase na manutenção dos gradientes iônicos transmembranares.

u) Explicar os efeitos celulares da ativação ou inibição da bomba de $\mathrm{Na}^{+} / \mathrm{K}^{+}$ATPase, por diferentes fatores (v.g. íons, hormônios, baixas temperaturas, anóxia, fármacos, venenos metabólicos).

v) Aplicar os fundamentos da eletrofisiologia na explicação de:

$\mathrm{v}_{1}$ ) certas alterações fisiopatológicas (v.g. no diabetes mellitus; na insuficiência renal crônica). $\mathrm{v}_{2}$ ) determinados fenômenos celulares (v.g. inativação de canais de $\mathrm{K}^{+}{ }_{\text {ATP }}$ para a secreção de insulina pelas células beta; ativação farmacológica desses canais).

\section{4- PLANO geRAL DO INSTRUMENTO}

O presente estudo consiste, basicamente, de uma seqüência lógica, articulada e hierarquizada de questões objetivas de múltipla escolha, de resposta única, que visam estimular o estudante a descobrir, por meio do raciocínio lógico-dedutivo, as bases físico-químicas da geração e manutenção dos potenciais de membrana. Trata-se de uma proposição deliberadamente elementar, mas que visa apresentar, precisamente, os fundamentos da Eletrofisiologia, de maneira a serem mais facilmente compreendidos. $\mathrm{O}$ instrumento inclui questões redundantes ou verificadoras, em ciclos, que permitem retomar, reavaliar e consolidar aspectos já enfocados, em momentos anteriores.

$\mathrm{Na}$ sua parte final, são apresentadas questões específicas, de cunho prático, em referência a variados setores da Fisiologia. São enfocados aspectos fisiopatológicos e farmacológicos, visando demonstrar: (a) o alcance deste estudo e (b) algumas das possíveis aplicações dos conhecimentos obtidos na Eletrofisiologia básica.

Diversos insets são incluídos, visando reforçar conceitos essenciais, bem como destacar aspectos interessantes sobre o tema.

O gabarito das questões e as referências bibliográficas encerram o estudo. Por se tratar de um instrumento de ensino-aprendizagem e, não, de uma simples avaliação, cada resposta deve ser conferida e, eventualmente, reavaliada após a análise de cada questão.

Para efeitos didáticos, são aqui consideradas padrões as concentrações extracelulares de $\mathrm{K}^{+}=4 \mathrm{mM}$; $\mathrm{Na}^{+}=140 \mathrm{mM} \mathrm{e} \mathrm{Cl}^{-}=130 \mathrm{mM}$, bem como os valores intracelulares de $\mathrm{K}^{+}=140 \mathrm{mM} ; \mathrm{Na}^{+}=15 \mathrm{mM} \mathrm{e}$ $\mathrm{Cl}^{-}=10 \mathrm{mM}$.

\section{5- INSTRUMENTO}

Condição I: Uma célula teórica (I), cuja membrana plasmática é permeável unicamente ao $\mathrm{K}^{+}$, apresenta um gradiente transmembranar desse íon, de $140 \mathrm{mM}$ (intracelular) para $4 \mathrm{mM}$ (extracelular). Ambos os compartimentos são eletroneutros. Para simplificação didática, os ânions (contra-íons) e os demais cátions foram omitidos.

$$
\begin{aligned}
& {\left[\mathrm{K}^{+}\right]_{\mathrm{i}}=140 \mathrm{mM}} \\
& {\left[\mathrm{K}^{+}\right]_{\mathrm{e}}=4 \mathrm{mM}}
\end{aligned}
$$

Partindo-se da situação hipotética em que não há diferenças de cargas elétricas entre o intra e o extracelular - a diferença de potencial é zero gunta-se:

1- O fluxo inicial resultante de $\mathrm{K}^{+}$para fora da célula, por difusão, é determinado, essencialmente, pelo gradiente do potencial:

a) Elétrico.

b) Químico (i.e. gradiente de concentração).

c) Eletroquímico.

\section{A difusão de íons a favor de gradientes de concen- tração é a mais importante causa de manifestação elétrica em sistemas biológicos ${ }^{4}$.}

2- A carga elétrica resultante, no interior da célula, com o passar do tempo será:
a) Nula.
b) Positiva.
c) Negativa. 
Apesar da separação de cargas - capacitância — da membrana plasmática, o princípio da neutralidade elétrica não é violado, já que o volume citoplasmático e o fluido extracelular são eletricamente neutros, com igual número de cargas positivas e negativas. A separação de cargas ocorre somente em uma região muito estreita, com menos de $1 \mu \mathrm{m}$ de espessura, em ambos os lados da membrana (nuvem iônica superficial). Além disso, o número de cargas separadas representa uma fração insignificante do total de cargas positivas e negativas intracelulares ${ }^{14}$.

3- A força que se opõe à saída de $\mathrm{K}^{+}$resulta do gradiente de potencial:
a) Elétrico
b) Químico
c) Eletroquímico

A combinação de gradientes iônicos transmembranares com permeabilidade diferencial a íons é a base para a geração de diferenças de voltagem.

Potencial de difusão é a diferença de voltagem originada da separação de cargas resultante da difusão de partículas carregadas em uma solução.

Membranas biológicas comportam-se como capacitores elétricos porque separam e acumulam cargas elétri$\operatorname{cas}^{5}$.

3a- Faça quatro esquemas semelhantes àquele da figura acima (célula teórica I). No $1^{\circ}$ esquema, indique a situação inicial (tempo = zero). No $4^{\circ}$, indique a situação de equilíbrio. Em cada esquema, indique: (a) as alterações progressivas de carga elétrica, no intra e no extracelular; (b) usando vetores traçados em diferentes padrões ou cores, indique as forças dos dois gradientes, bem como a força resultante, para difusão do potássio; (c) indique, para cada esquema, um valor arbitrário e coerente de potencial membranar resultante, no intervalo entre zero e $-95 \mathrm{mV}$.

4- Na questão 3, o gradiente de potencial elétrico cresce, a partir do instante zero, porque:

a) Parte dos ânions intracelulares ficam sem os seus contra-íons (princípio da eletroneutralidade).

b) O gradiente de potencial químico, i.e., gradiente de concentração, decresce rapidamente.

c) O gradiente de potencial químico decresce lentamente.
Em conjunto, as forças dos gradientes de potencial químico e de potencial elétrico somam-se algebricamente, resultando no que se conhece como gradiente eletroquímico.

5- O gradiente de potencial elétrico crescerá até que:

a) As concentrações de $\mathrm{K}^{+}$se igualem, através da membrana.

b) Ocorra a inversão das concentrações de $\mathrm{K}^{+}$, através da membrana.

c) A força do gradiente de potencial químico existente seja contrabalançada pela força do gradiente de potencial elétrico.

O gradiente de potencial elétrico, criado pela difusão do $\mathrm{K}^{+}$, impede a continuação desse processo de difusão, sendo atingido rapidamente um equilíbrio, no qual a força de difusão, no sentido do meio extracelular, criada pela diferença de concentração, é equilibrada por uma força elétrica, agindo no sentido oposto. A quantidade de íon que se move através da membrana - isolante dielétrico — é balanceada por uma quantidade igual do contra-íon, no outro lado da membrana. A membrana é literalmente carregada ao potencial de equilíbrio e age como um capacitor ${ }^{15}$.

6- $\mathrm{O}$ estado atingido, quando a força do gradiente de potencial elétrico chega ao seu máximo, denomina-se equilíbrio:
a) Químico.
b) Elétrico.
c) Eletroquímico.

A quantidade de $\mathrm{K}^{+}$que deixa a célula, para produzir o potencial de equilíbrio, é tão pequena que não pode ser medida quimicamente, apesar do substancial efeito elétrico que provoca. Assim, basta que apenas 1/100 000 (i.e., $0,001 \%$ ) do $\mathrm{K}^{+}$intracelular se difunda através da membrana celular para estabelecer o potencial de equilíbrio eletroquímico $\left(\mathrm{E}_{\mathrm{K}+}\right)(v . g .-90 \mathrm{a}-100 \mathrm{mV})$. Para alterar o potencial de membrana em $100 \mathrm{mV}$, há necessidade de um aumento de apenas cerca de 6000 cargas positivas em um lado da membrana e de 6000 cargas negativas do outro lado, por micrometro quadrado ${ }^{15,16}$.

7- Nesse equilíbrio, medindo-se os fluxos de difusão do potássio através da membrana, constata-se que:

a) A sua saída da célula (efluxo) é maior que a entrada (influxo).

b) Entrada e saída se equivalem.

c) A entrada na célula é maior que a saída. 
No meio extracelular, a quantidade de cátions excede a de ânions em apenas 1 picomol, ocorrendo o inverso no meio intracelular. Tal quantidade de cátions de um lado da membrana, $e$ igual quantidade de ânions do outro lado, representa a distância, em relação à eletroneutralidade, de cada lado da membrana ${ }^{15}$.

8- A diferença de potencial que pode ser medida nessa condição de equilíbrio é denominada potencial de equilíbrio:
a) Químico.
b) Elétrico.
c) Eletroquímico.

Quando a membrana se encontra no potencial de equilíbrio eletroquímico de um íon, embora não haja fluxo resultante desse íon, o mesmo se difunde continuamente através da membrana, nos dois sentidos.

9- Se, de alguma forma, a partir do estado de equilíbrio eletroquímico do $\mathrm{K}^{+}$, elevássemos instantaneamente a quantidade de cargas negativas dentro da célula (hiperpolarizássemos a célula), os fluxos de $\mathrm{K}^{+}$, transitoriamente, sofreriam as seguintes alterações:

a) Redução do influxo e aumento do efluxo.

b) Aumento do influxo e redução do efluxo.

c) Aumento do influxo e manutenção do efluxo.

Potenciais bioelétricos podem ser tanto a causa quanto o resultado dos processos de transporte iônico ${ }^{10}$.

É importante notar que, ao se ajustar o potencial celular para um valor maior do que o potencial de equilíbrio eletroquímico do íon, o fluxo resultante do íon se inverte, ocorrendo do compartimento onde está menos concentrado para aquele de maior concentração, sendo esse fluxo ascendente determinado pela força elétrica imposta.

10- Se, de alguma forma, a partir do estado de equilíbrio eletroquímico do $\mathrm{K}^{+}$, reduzíssemos a quantidade de cargas negativas dentro da célula (despolarizássemos a célula), os fluxos de $\mathrm{K}^{+}$, transitoriamente, sofreriam as seguintes alterações:

a) Manutenção do influxo e aumento do efluxo.

b) Aumento do influxo e redução do efluxo.

c) Redução do influxo e aumento do efluxo.

$O$ acúmulo relativo de íons $\mathrm{K}^{+}$no interior das células, bem como a relativa exclusão do $\mathrm{Na}^{+}$desse compartimento, originam um potencial químico, crucial para as atividades que, no conjunto, representam a energética celular. Preservar essas diferenças de distribuição iônica significa manter a capacidade de a célula gerar potenciais de difusão, potenciais de membrana e, no caso das células excitáveis, potenciais de ação. Assim, os gradientes iônicos são a base físico-química dos fenômenos elétricos celulares.

A quantidade de íons $\left(\mathrm{Na}^{+}\right.$ou $\left.\mathrm{K}^{+}\right)$segregada em um dos lados da membrana pode ser comparada ao reservatório de água represada por uma barragem de usina hidrelétrica. Quanto maior a quantidade (concentração) armazenada e, portanto, maior o gradiente, maior é o potencial. Se a quantidade armazenada se reduz, diminui a capacidade de geração energética. $O$ gradiente representa o potencial energético. Por conseguinte, a magnitude do potencial de membrana será tanto maior quanto maiores forem a concentração e o gradiente químico do íon mais permeante através da membrana.

Em analogia com a barragem e as comportas de uma usina hidrelétrica, nas células tudo se passa como se a membrana plasmática normalmente represasse as correntes iônicas e controlasse precisamente o fluxo por meio da seleção dos íons que passam pelos canais.

Condição II: Acrescentando, a partir de agora, uma outra célula teórica (II), permeável unicamente ao $\mathrm{K}^{+}$, que apresenta um gradiente desse íon, de $140 \mathrm{mM}$ (intracelular) para $8 \mathrm{mM}$ (extracelular), pergunta-se:

$$
\begin{aligned}
& {\left[\mathrm{K}^{+}\right]_{\mathrm{i}}=140 \mathrm{mM}} \\
& {\left[\mathrm{K}^{+}\right]_{\mathrm{e}}=8 \mathrm{mM}}
\end{aligned}
$$

11- O maior gradiente de potencial químico é encontrado na célula teórica:
a) II.
b) I.
c) Não há diferença de gradiente.

12- Sendo assim, na situação de equilíbrio, a força do gradiente de potencial elétrico será maior na célula teórica:
a) I.
b) II.
c) Não haverá diferença nessa força.

13- Como conseqüência, a célula teórica que apresentará maior polaridade será a: 
a) I.

b) II.

c) Não haverá célula com maior polaridade que a outra.

Torna-se evidente que, a um maior gradiente de potencial químico corresponde um maior gradiente de potencial elétrico e, portanto, um maior potencial de equilíbrio eletroquímico. Esse balanço de forças devidas aos gradientes de potencial elétrico e químico é descrito pela equação de Nernst.

Os valores de potenciais de equilíbrio eletroquímico de íons podem ser calculados por meio da Equação de Nernst (Walther Hermann Nernst, 1864-1941).

$$
\begin{aligned}
& \mathrm{E}_{\text {cátion }}=-2,303(\mathrm{RT} / \mathrm{zF}) \cdot \log \left\{[\text { íon }]_{\mathrm{i}} /[\text { íon }]_{\mathrm{e}}\right\} \\
& \mathrm{E}_{\text {ânion }}=-2,303(\mathrm{RT} / \mathrm{zF}) \cdot \log \left\{[\text { íon }]_{\mathrm{e}} /[\text { íon }]_{\mathrm{i}}\right\}
\end{aligned}
$$

Assim, na temperatura de $37^{\circ} \mathrm{C}$ :

$\mathrm{E}_{\text {ion }}=-61,5 . \log \left\{[\text { íon }]_{\mathrm{i}} /[\text { [ion }]_{\mathrm{e}}\right\}$, para os íons $\mathrm{K}^{+}, \mathrm{Na}^{+}$e outros cátions.

$$
\mathrm{E}_{\text {ion }}=-61,5 . \log \left\{[\text { íon }]_{\mathrm{e}} /[\text { íon }]_{\mathrm{i}} \succ \text {, para o íon } \mathrm{Cl}^{-}\right.
$$
e outros ânions.

$\mathrm{E}_{\text {ion }}$ é a diferença do potencial de equilíbrio elétrico que se opõe exatamente à energia química do gradiente químico.

$\mathrm{Na}$ temperatura de $20^{\circ} \mathrm{C}$, o valor da constante é -58 , ao invés de $-61,5$.

Interpreta-se fisicamente a equação de Nernst como a contraposição entre duas forças: uma, a força gerada pela tendência que o íon tem de se difundir de uma solução mais concentrada para outra menos concentrada; outra, a oposição do campo elétrico gerado na junção das duas soluções. $O$ sentido do campo elétrico é tal que anula o movimento resultante do íon.

14- Utilizando a equação de Nernst, os valores calculados do potencial de equilíbrio eletroquímico do $\mathrm{K}^{+}$, das células teóricas I e II, são respectivamente, (na temperatura de $37^{\circ} \mathrm{C}$ ):

a) $-41,2 \mathrm{mV}$ e $-33,2 \mathrm{mV}$.

b) $-94,9 \mathrm{mV}$ e $-76,4 \mathrm{mV}$.

c) $-89,6 \mathrm{mV}$ e $-72,1 \mathrm{mV}$.

O potencial de qualquer célula é medido usando-se o meio extracelular como referência (neutro ou potencial zero).
15- A célula teórica I mostra-se mais polarizada que a célula II, por apresentar:

a) Menor gradiente de potencial químico.

b) Maior gradiente de potencial químico.

c) Maior permeabilidade da membrana ao $\mathrm{K}^{+}$.

Quando potenciais celulares são comparados, consideram-se os valores absolutos. Portanto, v.g., o potencial de - $80 \mathrm{mV}$ é menor que o potencial de-90 $\mathrm{mV}$.

16- Excetuando-se os astrócitos, as células vivas em geral estão, constantemente, sofrendo uma perda líquida de $\mathrm{K}^{+}$por difusão (efluxo maior que influxo) porque apresentam um potencial de membrana:

a) Menor que o potencial de equilíbrio eletroquímico do $\mathrm{K}^{+}$.

b) Maior que o potencial de equilíbrio eletroquímico do $\mathrm{K}^{+}$.

c) Igual ao potencial de equilíbrio eletroquímico do $\mathrm{K}^{+}$.

Para um determinado íon, o potencial de membrana que faz cessar a difusão resultante desse íon através da membrana é denominado potencial de equilíbrio eletroquímico $\left(\mathrm{E}_{\text {ion }}\right)^{15}$.

17- Nos astrócitos, o potencial de membrana é igual ao potencial de equilíbrio eletroquímico do $\mathrm{K}^{+}$. Esse fato indica que:

a) $\mathrm{O}$ gradiente de potencial químico do $\mathrm{K}^{+}$é maior do que o gradiente do $\mathrm{Na}^{+}$e do $\mathrm{Cl}^{-}$.

b) A permeabilidade da membrana ao $\mathrm{K}^{+}$é maior do que aos demais íons.

c) A membrana dessas células é permeável somente ao $\mathrm{K}^{+}$.

Quando a membrana é permeável a um único íon, o potencial de membrana que se estabelece é um potencial de equilíbrio eletroquímico ( $E_{\text {ion }}$ ) e que deverá se manter indefinidamente.

18- Como conseqüência dessa característica membranar dos astrócitos, mencionada na questão 17 , nessas células:

a) Não há fluxo resultante de $\mathrm{K}^{+}$.

b) Prevalece a entrada de $\mathrm{K}^{+}$.

c) Prevalece a saída de $\mathrm{K}^{+}$.

Em uma célula cuja membrana é permeável somente ao $\underline{\mathbf{K}}^{+}$, nenhuma energia metabólica é necessária para manter os gradientes iônicos transmembranares ${ }^{14}$. 
As questões 19 a 26 referem-se à proposição abaixo:

Considere um paciente portador de insuficiência renal crônica, que manifesta hipercalemia (aumento da concentração plasmática do $\mathrm{K}^{+}$). Assim, cada parâmetro celular especificado abaixo sofrerá:

19- Gradiente de potencial químico do $\mathrm{K}^{+}$:
a) Aumento.
b) Redução.
c) Manutenção.

20- Saída de $\mathrm{K}^{+}$por difusão:
a) Aumento.
b) Diminuição.
c) Manutenção

21- Concentração intracelular de $\mathrm{K}^{+}$:
a) Ínfima diminuição.
b) Manutenção.
c) Ínfimo aumento.

22- Número de cargas negativas, no meio intracelular, junto à membrana plasmática:
a) Diminuição.
b) Aumento.
c) Manutenção.

Músculos esqueléticos e fígado atuam destacadamente na função de tamponar $0 \mathrm{~K}^{+}$, contribuindo para a manutenção da concentração extracelular desse íon ${ }^{17}$.

23- Negatividade intracelular:
a) Aumento.
b) Diminuição.
c) Manutenção.

24- Potencial de membrana:
a) Diminuição.
b) Aumento.
c) Manutenção.

25- Polaridade da célula:
a) Aumento.
b) Diminuição.
c) Manutenção.

26- Concluindo: quando ocorre aumento da concentração extracelular de um sal de $\mathrm{K}^{+}$, a célula:

a) Mantém o seu potencial de membrana b) Sofre hiperpolarização.

c) Sofre despolarização.

Até a $2^{\mathrm{a}}$ Grande Guerra Mundial, não se reconhecia que 0 aumento do $\mathrm{K}^{+}$sérico (hipercalemia), associado com lesões graves, podia provocar a morte, devido à despolarização de células cardíacas, nas quais o $\mathrm{K}^{+}$é 0 íon permeante.

Hipercalemia pode provocar a morte por parada cardíaca ou fibrilação ventricular ${ }^{17}$.

Condição III. Considere agora uma célula teórica (III), cuja membrana plasmática é permeável unicamente ao $\mathrm{Na}^{+}$, como esquematizado abaixo:

$$
\begin{aligned}
{\left[\mathrm{Na}^{+}\right]_{\mathrm{i}} } & =15 \mathrm{mM} \\
{\left[\mathrm{Na}^{+}\right]_{\mathrm{e}} } & =140 \mathrm{mM}
\end{aligned}
$$

Partindo-se da situação hipotética, em que não há diferença de cargas elétricas entre o intra e o extracelular, pergunta-se:

27- $\mathrm{O} \mathrm{Na}^{+}$entrará na célula até que:
a) As suas concentrações se igualem.
b) Seja atingido o seu equilíbrio eletroquímico.
c) Seja atingido o seu equilíbrio elétrico.

28- Na questão anterior, o potencial que pode ser medido, na situação de equilíbrio, é denominado potencial de equilíbrio:
a) Elétrico do $\mathrm{Na}^{+}$.
b) Químico do $\mathrm{Na}^{+}$.
c) Eletroquímico do $\mathrm{Na}^{+}$.

Determina-se o potencial de equilíbrio para um íon igualando-se a força de difusão sobre esse íon (proporcional ao gradiente de concentração) à força elétrica (proporcional ao campo elétrico) que age sobre ele. $O$ resultado é o potencial de equilíbrio eletroquímico do íon $\left(\mathrm{E}_{\text {ion }}\right)$ (potencial de Nernst).

29- Utilizando a equação de Nernst, o potencial de equilíbrio eletroquímico do $\mathrm{Na}^{+}\left(\mathrm{E}_{\mathrm{Na}^{+}}\right)$, calculado para a temperatura de $37^{\circ} \mathrm{C}$, será:
a) $59,7 \mathrm{mV}$
b) $-59,7 \mathrm{mV}$
c) $56,3 \mathrm{mV}$ 
30- As células em geral estão, constantemente, ganhando $\mathrm{Na}^{+}$por difusão (influxo maior que efluxo), porque apresentam um potencial de membrana:

a) Próximo do potencial de equilíbrio eletroquímico do $\mathrm{Na}^{+}$.

b) Igual ao potencial de equilíbrio eletroquímico do $\mathrm{Na}^{+}$.

c) Distante do potencial de equilíbrio eletroquímico do $\mathrm{Na}^{+}$.

31- As células, em geral, estão permanentemente, perdendo $\mathrm{K}^{+}$e ganhando $\mathrm{Na}^{+}$, por difusão. Entretanto, os gradientes iônicos não se alteram, ao longo do tempo, porque:

a) A bomba de $\mathrm{Na}^{+} / \mathrm{K}^{+}$ATPase repõe os íons que fluem por difusão.

b) O número de íons que flui por difusão é desprezível.

c) Sais de $\mathrm{Na}^{+}$e de $\mathrm{K}^{+}$se dissociam e repõem os íons livres que se difundem.

\footnotetext{
A bomba de $\mathrm{Na}^{+} / \mathrm{K}^{+}{ }_{\text {ATPase }}$ é mais ativa quando aumentam as concentrações extracelulares de potássio e/ou as concentrações intracelulares de $\mathrm{Na}^{+}$.
}

Clampear a voltagem significa, por meio da injeção de corrente elétrica, manter constante a diferença de voltagem transmembranar.

32- Se, experimentalmente, por meio de um clampeamento de voltagem, fizermos com que o potencial de membrana de uma célula real se torne igual ao potencial de equilíbrio eletroquímico do $\mathrm{K}^{+}$, a difusão resultante desse íon:
a) Ocorrerá de fora para dentro da célula.
b) Ocorrerá de dentro para fora da célula.
c) Será nula.

33- Se, por meio de um clampeamento de voltagem, fizermos com que o potencial de membrana de uma célula real se torne mais negativo que o potencial de equilíbrio eletroquímico do $\mathrm{K}^{+}$, a difusão resultante desse íon:
a) Será nula.
b) Ocorrerá de fora para dentro da célula.
c) Ocorrerá de dentro para fora da célula.

\section{A força do gradiente de potencial elétrico é capaz de promover a difusão de um íon do meio onde ele está menos concentrado para o meio de maior concentração desse íon.}

Quando as células excitáveis (v.g. neurônios, miócitos, células endócrinas inter alia) estão quiescentes, o seu potencial de membrana $\left(V_{m}\right)$ apresenta valor constante, sendo denominado potencial de repouso.

34- No potencial de repouso celular (potencial de membrana) das células em geral, a força elétrica é suficiente para impedir que haja uma saída resultante de $\mathrm{K}^{+}$, por difusão?
a) Não é suficiente.
b) É exatamente suficiente.
c) É mais do que suficiente.

Condição IV: Considerando a célula teórica abaixo (IV), permeável unicamente ao $\mathrm{Cl}^{-}$, pergunta-se:

$$
\begin{aligned}
& {\left[\mathrm{Cl}^{-}\right]_{\mathrm{i}}=10 \mathrm{mM}} \\
& {\left[\mathrm{Cl}^{-}\right]_{\mathrm{e}}=130 \mathrm{mM}}
\end{aligned}
$$

35- $\mathrm{O}$ fluxo resultante de $\mathrm{Cl}^{-}$através da membrana plasmática determinará, com o tempo, o aparecimento de um valor de potencial de membrana:
a) Positivo.
b) Negativo.
c) De equilíbrio químico.

36- A partir do início da difusão de $\mathrm{Cl}^{-}$, a força que se opõe a esse fluxo é resultante do gradiente de potencial:
a) Elétrico.
b) Químico.
c) Eletroquímico.

37- $\mathrm{O}$ fluxo resultante de $\mathrm{Cl}^{-}$, através da membrana, ocorrerá até:
a) O equilíbrio químico.
b) O equilíbrio elétrico.
c) Que as forças devidas ao gradiente de poten- cial químico e ao gradiente de potencial elétri- co sejam iguais e de sentidos opostos.

38- Utilizando a equação de Nernst, o potencial de equilíbrio eletroquímico do cloro $\left(\mathrm{E}_{\mathrm{Cl}^{-}}\right)$, calculado para a temperatura de $37^{\circ} \mathrm{C}$, será:
a) $-68,5 \mathrm{mV}$.
b) $68,5 \mathrm{mV}$.
c) $-64,6 \mathrm{mV}$. 
A equação de Nernst permite calcular a diferença de potencial elétrico que determina o equilíbrio de um íon através de uma membrana.

39- Quando a força devida ao gradiente de potencial químico, que promove a difusão de um íon num sentido da membrana, é contrabalançada pela força devida ao gradiente de potencial elétrico, em sentido oposto, podemos afirmar que esse íon está em equilíbrio:
a) Químico.
b) Elétrico.
c) Eletroquímico.

40- A diferença de potencial que se pode medir nessa situação é denominada potencial de equilíbrio:
a) Eletroquímico
b) Químico.
c) Elétrico. Hodgkin e Katz ou, mais tipicamente, equação de Goldman é, essencialmente, uma versão expandida da equação de Nernst, que leva em conta a permeabilidade iônica individual (P íon).
A equação do campo constante de Goldman-
b) $-66,7 \mathrm{mV}$.
c) $-20,2 \mathrm{mV}$.

Enquanto a permeabilidade é determinada pelo estado da membrana, a condutância depende, também, das concentrações iônicas ${ }^{14}$.

42- Se a concentração de $\mathrm{K}^{+}$nos líquidos extracelulares (LEC) subir para $8 \mathrm{mM}$, a $37^{\circ} \mathrm{C}$, mantidas as permeabilidades relativas a cada íon, o potencial de membrana dessa célula será:
a) $-60,4 \mathrm{mV}$.
b) $-18,7 \mathrm{mV}$.
c) $-64,0 \mathrm{mV}$

Injeção endovenosa de solução concentrada de KClé letal e tem sido utilizada em episódios de eutanásia. Aumento de 10 vezes na concentração de $K^{+}$no LEC elimina o potencial de repouso e torna inexcitável o miocárdio. $O$ coração cessa seus batimentos, em diástole.

43- Portanto, mais uma vez fica demonstrado que o aumento da concentração extracelular de $\mathrm{K}^{+}$provoca:
a) Hiperpolarização.

b) Despolarização.

c) Manutenção do potencial.

Operando-se as equações de Nernst e de Goldman pode-se constatar que, enquanto o aumento da concentração de K $\mathrm{K}^{+}$no LEC pro-

Condição V. Imagine que o retângulo abaixo represente uma célula muscular, nas condições indicadas, e responda às questões subseqüentes, considerando a temperatura de $37^{\circ} \mathrm{C}$.

A capacitação dos espermatozóides bovinos e de camundongos é acompanhada

$$
\begin{array}{ll}
{\left[\mathrm{K}^{+}\right]_{\mathrm{i}}=140 \mathrm{mM}} & {\left[\mathrm{Na}^{+}\right]_{\mathrm{i}}=15 \mathrm{mM} \quad\left[\mathrm{Cl}^{-}\right]_{\mathrm{i}}=10 \mathrm{mM}} \\
{\left[\mathrm{K}^{+}\right]_{\mathrm{e}}=4 \mathrm{mM}} & {\left[\mathrm{Na}^{+}\right]_{\mathrm{e}}=140 \mathrm{mM}\left[\mathrm{Cl}^{-}\right]_{\mathrm{e}}=130 \mathrm{mM}}
\end{array}
$$

voca despolarização celular, sua redução acarreta a hiperpolarização da célula.

de hiperpolarização da membrana plasmática, de -33 para $-66 \mathrm{mV}$ e de -38 para $-55 \mathrm{mV}$, respectivamente $^{18}$.

41- Considerando que a permeabilidade relativa da membrana aos íons $\mathrm{K}^{+}, \mathrm{Na}^{+}$e $\mathrm{Cl}^{-}$seja igual a: 1: $0,04: 0,45$, o potencial de membrana dessa célula, a $37^{\circ} \mathrm{C}$, é:

a) $-70,7 \mathrm{mV}$.
44- Se alterarmos a permeabilidade relativa aos íons $\mathrm{K}^{+}, \mathrm{Na}^{+}$e Cl- para 1:20: 0,45, o potencial de membrana dessa célula, a $37^{\circ} \mathrm{C}$, será:

a) $46,2 \mathrm{mV}$ 
b) $49,7 \mathrm{mV}$

c) $43,5 \mathrm{mV}$

Pode-se concluir, portanto, que o aumento intenso da permeabilidade a um íon faz com que o valor do potencial de membrana se aproxime do potencial de equilíbrio eletroquímico desse íon. Esse conhecimento será fundamental quando se for estudar a geração do potencial de ação pelas células dotadas dessa capacidade (células excitáveis).

45- Se alterarmos a permeabilidade relativa da membrana aos íons $\mathrm{K}^{+}, \mathrm{Na}^{+}$e $\mathrm{Cl}^{-}$para 1: 0: 0 , o potencial de membrana dessa célula, a $37^{\circ} \mathrm{C}$, será igual ao:
a) $\mathrm{E}_{\mathrm{Na}}+$
b) $\mathrm{E}_{\mathrm{K}}+$
c) $\mathrm{E}_{\mathrm{Cl}^{-}}$

Simulações feitas com as equações de Nernst e de Goldman demonstram que, enquanto o potencial de equilíbrio eletroquímico de um íon depende da razão de concentração do íon através da membrana, o potencial de membrana, além de depender dessa razão, depende dos valores de concentração de cada íon, em cada um dos lados da membrana, além de ser dependente das permeabilidades relativas a cada íon.

$O$ valor do potencial de membrana, num dado instante, tende a aproximar-se do potencial de equilíbrio eletroquímico do íon para o qual a permeabilidade da membrana é maior. Quando apenas um íon transita através da membrana, seu gradiente de concentração determina o potencial de membrana.

46- Considerando-se a mesma célula da questão $\mathrm{n}^{\circ}$ 41 , agora submetida à temperatura de $20^{\circ} \mathrm{C}$, o potencial de membrana será:
a) $-19,1 \mathrm{mV}$.
b) $66,7 \mathrm{mV}$.
c) $-66,7 \mathrm{mV}$.

47- Conclui-se, portanto, que a redução da temperatura determina:
a) Hiperpolarização celular.
b) Despolarização da membrana.
c) Manutenção do potencial de membrana.

$O$ valor do potencial de membrana celular é diferente, entre diferentes células. Isto se deve tanto a diferenças de gradientes iônicos quanto a diferentes permeabilidades relativas aos íons, entre as diferentes células.
Enquanto nas hemácias é de $-6 \mathrm{mV}$, nos hepatócitos é de $-28 \mathrm{mV}$ e nas células cardíacas está em torno de $-86 \mathrm{mV}^{15,19}$. Nas células epiteliais humanas é de -20 $\mathrm{mV}^{20}$. Adipócitos têm potencial de $-\mathbf{5 8} \mathrm{mV}^{21}$. Nas células beta pancreáticas em repouso, o potencial de membrana varia entre $-45 \mathrm{mV}$ e $-60 \mathrm{mV}^{22}$. Em células musculares e neurônios o potencial de membrana aproxima-se do potencial de equilíbrio eletroquímico do $\mathrm{K}^{+}$, enquanto em hemácias aproxima-se do potencial de equilíbrio do $\mathrm{Cl}^{-}$.

48- Em uma célula que está no seu potencial de repouso, existem gradientes atuantes para a entrada de $\mathrm{Na}^{+}$?
a) $\mathrm{Sim}$.
b) Não.
c) Em parte.

Curiosamente, nas algas marinhas o potencial de membrana pode ser de $-170 \mathrm{mV}$ (na Acetabulária) até 17 mV (na Valonia ventricosa) ${ }^{10}$.

49- A diferença entre o potencial de repouso e o potencial de equilíbrio eletroquímico do $\mathrm{Na}^{+}$, nas células em geral, é:
a) Desprezível.
b) Pequena.
c) Muito grande.

50- Em uma célula que está no seu potencial de repouso, quais são os gradientes para a difusão de $\mathrm{Na}^{+}$?
a) Gradiente de potencial químico.
b) Gradiente de potencial elétrico.
c) Ambos os gradientes.

Nas células animais, o potencial de membrana desempenha um papel vital em inúmeros processos fisiológicos, tais como a sinalização elétrica em células excitáveis, transporte de nutrientes acoplado ao $\mathrm{Na}^{+}$, no intestino delgado, contração muscular, função cerebral, percepção sensorial, secreção de neurotransmissores, geração pós-sináptica de potenciais de ação, sinalização celular, secreção hormonal, secreção de $\mathrm{Cl}^{-}$pelo epitélio das vias aéreas e o transporte iônico através das células epiteliais do néfron ${ }^{3,5}$.

51- Afirma-se que o potencial de membrana (potencial de repouso) é um potencial dissipativo e, não, um potencial de equilíbrio eletroquímico de $\mathrm{Na}^{+}$ ou de $\mathrm{K}^{+}$porque, no potencial de membrana: 
a) Persistem os fluxos resultantes desses íons.

b) Ocorrem, apenas, trocas equivalentes de $\mathrm{Na}^{+}$ e $\mathrm{K}^{+}$.

c) Com o passar do tempo, os gradientes químicos sofrem aumento.

O potencial dado pela equação de Goldman é um potencial dissipativo, que envolve fluxo difusional de íons, com redução da energia livre do sistema. Se o sistema for abandonado, ele evoluirá para uma condição de mínima energia livre. Se a membrana for permeável a todos os íons, o potencial final será igual a zero. Caso haja íons impermeantes, poderá ocorrer equilíbrio, com potencial final diferente de zero ${ }^{4}$.

52- No potencial de repouso $\left(\mathrm{V}_{\mathrm{m}}\right)$, a força gerada pelo gradiente de potencial elétrico é suficiente para impedir a difusão resultante de $\mathrm{Na}^{+}$?
a) $\mathrm{Sim}$.
b) Não.
c) Parcialmente.

O potencial de membrana nas células animais é gerado em grande parte pelo efluxo de $\mathrm{K}^{+}$através da membrana plasmática ${ }^{10}$.

53- O potencial de membrana de diversos tipos celulares se aproxima do valor do potencial de equilíbrio eletroquímico do $\mathrm{K}^{+}$, porque:

a) A permeabilidade relativa da membrana ao $\mathrm{K}^{+}$ é a maior, dentre os íons permeantes.

b) $\mathrm{O}$ gradiente de potencial químico do $\mathrm{K}^{+}$é o maior, dentre os três principais íons.

c) Ambas as razões acima.

Nas células musculares esqueléticas o potencial de membrana é controlado principalmente pelo gradiente de concentração de $\mathrm{K}^{+}$. Nessas células e, nas células em geral, $0 \mathrm{Cl}^{-}$ajusta passivamente suas concentracões no meio intracelular e extracelular, de acordo com o nível de potencial existente na membrana, i.e., a distribuição transmembranar do $\mathrm{Cl}^{-}$é uma conseqüência do potencial celular e, não, o oposto ${ }^{14,20}$.

54- Utilizando a equação de Goldman, considere uma situação especial em que a membrana seja permeável a um único íon (permeabilidade $=1$ ), sendo impermeável aos demais (permeabilidades $=$ zero). Calcule o potencial de membrana $\left(\mathrm{V}_{\mathrm{m}}\right)$. Em seguida, calcule, utilizando a equação de Nernst, o potencial de equilíbrio eletroquímico do íon $\left(\mathrm{E}_{\text {ion }}\right)$. Comparando os valores, pode-se concluir que, quando a membrana é permeável a um único íon, o potencial de membrana é:
a) Maior que o $E_{\text {ion }}$.
b) Menor que o $E_{\text {ion. }}$.
c) Igual ao $\mathrm{E}_{\text {ion }}$.

Enquanto no potencial de equilíbrio eletroquímico de um íon há equivalência entre influxo e efluxo iônico,o potencial de membrana é um potencial dissipativo, no qual os processos de difusão de $\mathrm{K}^{+}$e de $\mathrm{Na}^{+}$apresentam fluxo resultante, em um dos sentidos da membrana.

55- A bomba de $\mathrm{Na}^{+} / \mathrm{K}^{+}$ATPase transporta:
a) $\mathrm{Na}^{+}$para dentro e $\mathrm{K}^{+}$para fora da célula.
b) $\mathrm{Na}^{+}$para fora e $\mathrm{K}^{+}$para dentro da célula.
c) $\mathrm{Na}^{+}$e $\mathrm{K}^{+}$para dentro ou para fora, dependen- do dos gradientes químicos de cada íon.

Aumento da concentração extracelular de $\mathrm{K}^{+}$(hipercalemia) e/ou aumento da concentração intracelular de $\mathrm{Na}^{+}$estimulam a bomba de $\mathrm{Na}^{+} / \mathrm{K}^{+}{ }_{\text {ATPase }}{ }^{\circ}$

56- A função da bomba de $\mathrm{Na}^{+} / \mathrm{K}^{+}$ATPase é:

a) Manter os gradientes de potenciais químicos do $\mathrm{Na}^{+}$e do $\mathrm{K}^{+}$.

b) Manter a eletroneutralidade nos meios intra e extracelular.

c) Contrapor-se à manutenção de um potencial de repouso da membrana.

57- Nas células que têm bomba de $\mathrm{Na}^{+} / \mathrm{K}^{+}$ATPase eletrogênica, esta bomba transporta:

a) Dois $\mathrm{Na}^{+}$para fora e três $\mathrm{K}^{+}$para dentro da célula.

b) Dois $\mathrm{K}^{+}$para dentro e três $\mathrm{Na}^{+}$para fora.

c) Dois $\mathrm{Na}^{+}$para fora e um $\mathrm{K}^{+}$para dentro.

Os potenciais elétricos presentes nos seres vivos são, na maioria dos casos, gerados através de membranas, por mecanismos de difusão (potenciais de difusão), transportes ativos (potenciais de bombas eletrogênicas) ou ambos.

58- A bomba de $\mathrm{Na}^{+} / \mathrm{K}^{+}{ }_{\text {ATPase }}$, de muitas células, é eletrogênica porque:

a) Cria ou intensifica uma diferença de potencial através da membrana.

b) Mantém os gradientes iônicos. 
c) Consome energia metabólica das células.

Diferentes células podem apresentar comportamento diverso no tocante à natureza eletrogênica ou nãoeletrogênica da bomba de $\mathrm{Na}^{+} / \mathrm{K}^{+}{ }_{\text {ATPase }}{ }^{\cdot}$ Quando a bomba é eletrogênica, resulta um potencial de membrana ligeiramente mais negativo do que se esperaria da simples difusão de íons ${ }^{14}$.

Cerca de um terço do suprimento celular de ATP é gasto na bomba de $\mathrm{Na}^{+} / \mathrm{K}^{+}{ }_{\text {ATPase }}$, que mantém a elevada concentração intracelular de $\mathrm{K}^{+}$, necessária para a geração do potencial de membrana ${ }^{5}$. Em células musculares esqueléticas e em hemácias, cerca de três íons $\mathrm{Na}^{+}$ são bombeados para cada ATP hidrolisado ${ }^{15}$.

Estima-se que a bomba de $\mathrm{Na}^{+} / \mathrm{K}^{+}$ATPase gaste até $70 \%$ da quantidade total de ATP utilizada pelo encéfalo ${ }^{23}$.

59- A inibição da bomba de $\mathrm{Na}^{+} / \mathrm{K}^{+}$ATPase despolariza a célula porque esse procedimento:

a) Aumenta os gradientes dos potenciais químicos do $\mathrm{Na}^{+}$e do $\mathrm{K}^{+}$, através da membrana.

b) Reduz os gradientes dos potenciais químicos do $\mathrm{Na}^{+}$e do $\mathrm{K}^{+}$.

c) Altera as permeabilidades da membrana ao $\mathrm{Na}^{+}$ e ao $\mathrm{K}^{+}$.

Baixas concentrações de $\mathrm{Na}^{+}$intracelular e de $\mathrm{K}^{+}$extracelular inibem a bomba de $\mathrm{Na}^{+} / \mathrm{K}^{+}{ }_{\text {ATPase }}{ }^{\text {. }}$

Uma solução contendo glicose, insulina e $\mathrm{K}^{+}$— solução polarizante - tem uso clínico em infartos do miocárdio. A insulina e o $\mathrm{K}^{+}$ativam a bomba de $\mathrm{Na}^{+} / \mathrm{K}^{+}{ }_{\text {ATPase }}$. Essa bomba é energizada pelo ATP da oxidação da glicose. $O$ transporte da glicose nos tecidos musculares estriados é ativado pela insulina ${ }^{24}$.

\section{QUESTÕES PARA APLICAÇÃO DOS CONHE- CIMENTOS BÁSICOS}

Agora que você já estudou os aspectos básicos de Eletrofisiologia, está em condições de aplicar esses conhecimentos em situações novas, que fazem parte do estudo de diferentes áreas da Medicina Experimental (v.g. Endocrinologia, Neurologia, Cardiologia, Gastroenterologia, Nefrologia inter alia).

60- Nas células beta das ilhotas de Langerhans o metabolismo da glicose provoca aumento da razão ATP/ADP e determina o fechamento de canais de $\mathrm{K}_{\text {ATP }}^{+}$. Igualmente, sulfoniluréias - hipo- glicemiantes orais - determinam o fechamento desses canais. O efeito que essas substâncias provocam na membrana plasmática das células beta é a:
a) Hiperpolarização.
b) Despolarização.
c) Repolarização.

61- Diazoxida é um fármaco utilizado no tratamento de hiperinsulinemias. Esse agente provoca, na membrana plasmática das células beta pancreáticas, a abertura de canais de $\mathrm{K}^{+}{ }_{\text {ATP }}$ e, conseqüentemente:
a) Repolarização.
b) Despolarização.
c) Hiperpolarização.

62- Diabéticos descompensados manifestam perda do $\mathrm{K}^{+}$intracelular, em especial nas células da musculatura esquelética. Em conseqüência, o que ocorre com essas células?
a) Despolarização.
b) Repolarização.
c) Hiperpolarização.

63- A administração de insulina a um paciente com diabetes descompensado ativa a entrada de $\mathrm{K}^{+}$ nas células ( $v . g$. células musculares estriadas), por meio da bomba de $\mathrm{Na}^{+} / \mathrm{K}^{+}$ATPase . A conseqüência, para a membrana plasmática, é a:
a) Maior despolarização.
b) Estabilização do potencial de repouso.
c) Repolarização.

64- Ouabaína inibe e difenil-hidantoína ativa a bomba de $\mathrm{Na}^{+} / \mathrm{K}^{+}$ATPase Nas células em geral, as conseqüências da utilização terapêutica ou experimental desses fármacos são, respectivamente:
a) Despolarização; hiperpolarização.
b) Hiperpolarização; despolarização.
c) Despolarização; estabilização do potencial de repouso.

65- Diversos hormônios ativam a bomba de $\mathrm{Na}^{+} /$ $\mathrm{K}_{\text {ATPase }}^{+}$(v.g. adrenalina, noradrenalina, insulina, $\mathrm{T}_{3} / \mathrm{T}_{4}$ e corticosteróides). $\mathrm{O}$ efeito desses hormônios na membrana plasmática é a:
a) Despolarização.
b) Hiperpolarização.
c) Estabilização do potencial de repouso. 
66- A explicação de Prosser, para as ondas lentas (ritmo elétrico básico, com despolarizações periódicas) da musculatura lisa intestinal, baseia-se em uma flutuação, determinada geneticamente, de processos de oxi-redução, ligados ao Ciclo de Krebs, provocando redução do ATP disponível para a bomba de $\mathrm{Na}^{+} / \mathrm{K}^{+}{ }_{\text {ATPase }}$. O funcionamento dessa bomba eletrogênica altera o potencial de membrana, de tal maneira que:

a) Inibição da bomba despolariza a membrana, até gerar potenciais de ação (spikes).

b) Inibição da bomba estabiliza o potencial de membrana, gerando spikes.

c) Reativação da bomba despolariza a membrana, até gerar spikes.

67- A insuficiência renal crônica pode ser fatal, diante da menor excreção de potássio na urina. A morte decorre da:

a) Hiperpolarização das células do nodo sino-atrial.

b) Ativação da bomba de $\mathrm{Na}^{+} / \mathrm{K}^{+}$ATPase, provocada pelas alterações iônicas no LEC.

c) Despolarização das células do miocárdio.

Na década de 50, do século passado, quando ainda não se fazia hemodiálise, tentava-se salvar o doente fornecendo-lhe chicletes e aspirando-se o grande volume de saliva secretado.
68- Redução da concentração de $\mathrm{K}^{+}$no LEC (hipocalemia) pode provocar fraqueza muscular, câimbras e até paralisia. Tal fato pode ocorrer durante o uso de certos diuréticos (v.g. furosemida), caso não se reponha o $\mathrm{K}^{+}$, eliminado em excesso, na urina. Durante aquela redução, as células apresentam:

a) Despolarização.

b) Hiperpolarização.

c) Estabilização do potencial de repouso.

69- Em hemocentros, as bolsas de sangue são estocadas em temperaturas entre $1^{\circ} \mathrm{C}$ e $6^{\circ} \mathrm{C}$. Em conseqüência, é razoável esperar-se que ocorra:

a) Despolarização da membrana plasmática, nos elementos figurados (células).

b) Redução da concentração extracelular de $\mathrm{K}^{+}$.

c) Hiperpolarização celular.

70- $\mathrm{O}$ aumento da temperatura das bolsas de sangue, antes de uma transfusão, provoca:

a) Aumento do $\mathrm{Na}^{+}$intracelular.

b) Aumento do $\mathrm{K}^{+}$extracelular.

c) Repolarização celular.

\section{GABARITO}

$\begin{array}{ccccccc}\text { 1. b } & 11 . \mathrm{b} & 21 . \mathrm{c} & 31 . \mathrm{a} & 41 . \mathrm{a} & 51 . \mathrm{a} & 61 . \mathrm{c} \\ \text { 2. c } & 12 . \mathrm{a} & 22 . \mathrm{a} & 32 . \mathrm{c} & 42 . \mathrm{c} & 52 . \mathrm{b} & 62 . \mathrm{a} \\ \text { 3. a } & 13 . \mathrm{a} & 23 . \mathrm{b} & 33 . \mathrm{b} & 43 . \mathrm{b} & 53 . \mathrm{c} & 63 . \mathrm{c} \\ \text { 4. } \mathrm{a} & 14 . \mathrm{b} & 24 . \mathrm{a} & 34 . \mathrm{a} & 44 . \mathrm{a} & 54 . \mathrm{c} & 64 . \mathrm{a} \\ \text { 5. c } & 15 . \mathrm{b} & 25 . \mathrm{b} & 35 . \mathrm{b} & 45 . \mathrm{b} & 55 . \mathrm{b} & 65 . \mathrm{b} \\ \text { 6. c } & 16 . \mathrm{a} & 26 . \mathrm{c} & 36 . \mathrm{a} & 46 . \mathrm{c} & 56 . \mathrm{a} & 66 . \mathrm{a} \\ \text { 7. } \mathrm{b} & 17 . \mathrm{c} & 27 . \mathrm{b} & 37 . \mathrm{c} & 47 . \mathrm{b} & 57 . \mathrm{b} & 67 . \mathrm{c} \\ \text { 8. c } & 18 . \mathrm{a} & 28 . \mathrm{c} & 38 . \mathrm{a} & 48 . \mathrm{a} & 58 . \mathrm{a} & 68 . \mathrm{b} \\ 9 . \mathrm{b} & 19 . \mathrm{b} & 29 . \mathrm{a} & 39 . \mathrm{c} & 49 . \mathrm{c} & 59 . \mathrm{b} & 69 . \mathrm{a} \\ 10 . \mathrm{c} & 20 . \mathrm{b} & 30 . \mathrm{c} & 40 . \mathrm{a} & 50 . \mathrm{c} & 60 . \mathrm{b} & 70 . \mathrm{c}\end{array}$




\section{EXEMPLO DIDÁTICO DE RESPOSTA À QUESTÃO 3a}

tempo $=$ zero

\begin{tabular}{|c|c|c|}
\hline$\left[\mathrm{K}^{+}\right]_{\mathrm{i}}=140 \mathrm{mM}$ & $0 \mathrm{mV}$ \\
& & $\vdots$ \\
\hline$\left[\mathrm{K}^{+}\right]_{\mathrm{e}}=4 \mathrm{mM} \nabla$ & $\nabla$
\end{tabular}

Inicialmente (tempo = zero), a força do gradiente de potencial elétrico é zero. Sendo assim, a força resultante é igual à força do gradiente de potencial químico.

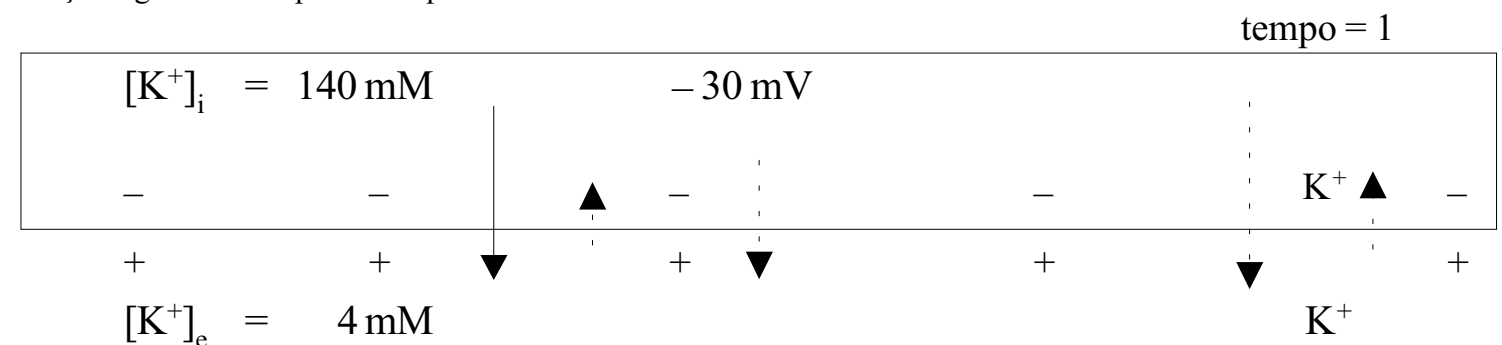

O efluxo resultante de $\mathrm{K}^{+}$(efluxo menos influxo) deixa seus contra-íons (negativos) no interior da célula, gerando a força do gradiente de potencial elétrico, de fora para dentro da célula $(-30 \mathrm{mV})$. A força resultante sofre redução. $\mathrm{O}$ efluxo de $\mathrm{K}^{+}$é maior que o seu influxo.

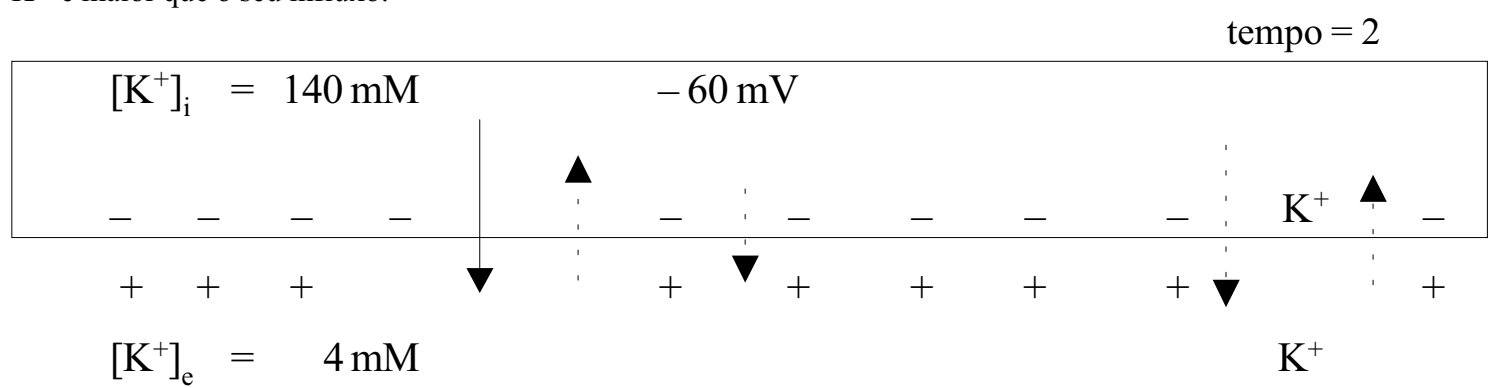

A continuidade do efluxo resultante de $\mathrm{K}^{+}$, embora de valor decrescente, promove aumento da força do gradiente do potencial elétrico $(-60 \mathrm{mV})$. A força resultante é progressivamente menor.

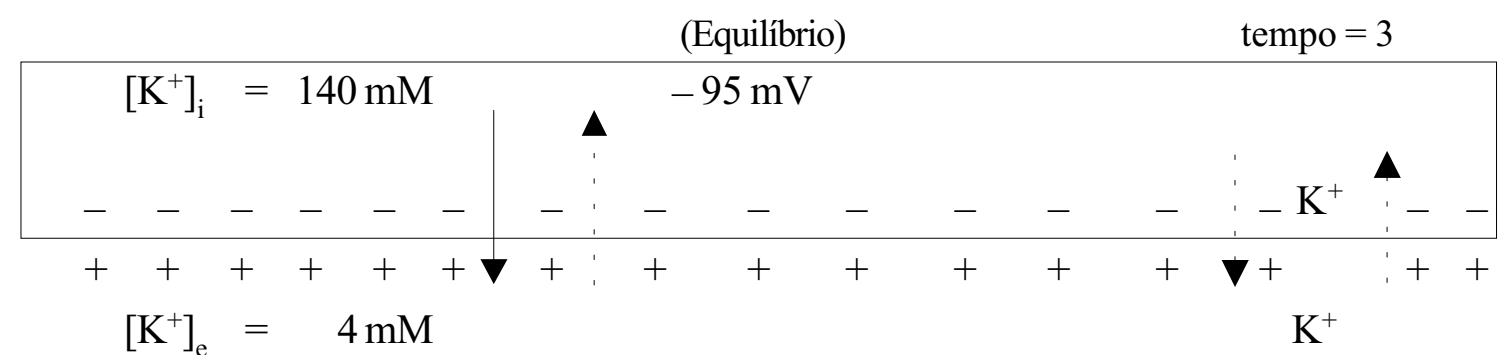

A força do gradiente do potencial elétrico atinge seu valor máximo $(-95 \mathrm{mV})$ e contrabalança a força do gradiente do potencial químico. A força resultante torna-se nula e se estabelece o equilíbrio eletroquímico. $\mathrm{O}$ valor do potencial de equilíbrio eletroquímico do $\mathrm{K}^{+}\left(\mathrm{E}_{\mathrm{K}_{+}}\right)$é $-95 \mathrm{mV}$. Efluxo e influxo de $\mathrm{K}^{+}$se igualam.

\begin{tabular}{|c|c|c|}
\hline $\begin{array}{l}\text { Força do gradiente de } \\
\text { potencial químico }\end{array}$ & $\boldsymbol{\Delta}$ & $\begin{array}{l}\text { Força do gradiente } \\
\text { de potencial elétrico }\end{array}$ \\
\hline
\end{tabular}


Delattre E. Eletrophysiology fundamentals: membrane potentials. Medicina (Ribeirão Preto) 2007; 40 (3): 378-93, july/sept.

ABSTRACT: Electrophysiology is of fundamental importance for the professionals in the medical field. However, there are difficulties in its understanding by students.Based in our teaching experience, we feel the need to help the student who is getting started in this subject or that wants to review it. Thus, we have prepared an easy, useable auto-instructional tool of teaching-learning, where the sequential mastery of the contents favors new cognitive acquisitions. The current tool aims at handling the chemical-physical principle of bioelectrogenesis supplying the basis to study neurophysiology, endocrinology and cardiac electrophysiology inter alia. Preceded by a theoretical introduction and objectives it presents a logical, articulated and hierarchical sequence of seventy objective, multi-choice questions, being fifty nine in the basic domain and eleven in the applied domain. They aim to stimulate the student to discover, by means of a logical-deductive reasoning, bioelectrical fundamentals of the generation and maintainance of the membranane potential. Parallel with the proposition contents, several reinforcing insets are placed about the essential concepts, or that are considered relevant or special applications of the subject. At the end an answer list is presented. The tool was used in student group activities with the biology area students with satisfactory results.

Keywords: Membrane Potentials. Electrophysiology. Biophysics. Teaching. Learning. Programmed Instruction.

\section{REFERÊNCIAS}

1 - Nolan WF. A problem-solving approach to teaching electrochemical driving force to undergraduates. Advan Physiol Edu 1990; 4: S1-S3.

2 - Stewart M. Helping students to understand that outward currents depolarize cells. Adv Physiol Edu 1999; 21: S62-S68.

3 - Wrigth SH. Generation of resting membrane potential. Advan Physiol Edu 2004; 28: 139- 42.

4 - Lacaz-Vieira F. Bioeletrogênese. In: Lacaz-Vieira , Malnic G, editores. Biofísica. Rio de Janeiro: Guanabara Koogan; 1981. p. 41-63.

5 - Moran WJ, Denton J, Wilson K, Williams M, Runge SW. A simple, inexpensive methods for teaching how membrane potentials are generated. Adv Physiol Edu 1999; 22: S51-S9.

6 - Manalis RS, Hastings L. Electrical gradients across an íonexchange membrane in sutdent's artificial cell. J Appl Physiol 1974; 36: 769-70.

7 - Thurman CL. Resting membrane potentials: a student test of alternate hypotheses. Adv Physiol Edu 1995; 14: 537-41.

8 - Silverthorn DU. Uncovering misconceptions about the resting membrane potential. Adv Physiol Edu 2002; 26: 69-71.

9 - Kurbel S. Simplified interpretation of the pacemaker potential as a tool for teaching membrane potential. Adv Physiol Edu 2003; 27: 159-61.

10 - Gutknecht J. The origin of bioelectrical potentials in plant and animal cells. Am Zoologist 1970; 10: 347-54.

11 - McDonough AA, Thompson CB, Youn JH. Skeletal muscle regulates extracellular potassium. Am J Physiol 2002; 282: F967-F74.

12 - Furtado MR. Balanço do potássio e sua regulação. In: Malnic G, Marcondes M. Fisiologia renal. São Paulo: EPU; 1986. p. 301-10.

13 - Mudado MA, Moreira TH, Cruz JS. O início da era dos canais iônicos. Ciência Hoje 2003; 33: 56-8.
14 - Koester J. Resting membrane potential and action potential. In: Kandel ER, Schwartz JH, Jessel TM. Principles of neural science. New York: Elsevier; 1985. p. 49-57.

15 - Devoe RD. Princípios de homeostasia celular. In: Mountcastle, VB. Fisiologia médica. Rio de Janeiro: Guanabara Koogan; 1978. p. 3-33.

16 - Vander AJ, Sherman JH, Luciano DS. Fisiologia humana. São Paulo: McGraw-Hill; 1981.

17 - Pettit GW, Vick RL. Contribution of pancreatic insulin to extrarenal potassium homeostasis: a two-compartment model. Am J Physiol 1974; 226: 319-24.

18 - Hernández-González EO, Sosnik J, Acevedo JJ, MendozaLujambio I, López-González I, Demarco I et al. Sodium and epithelial sodium channels participate in the capacitationassociated hyperpolarization in mouse sperm. J Biol Chem 2006; 281: 5623-33.

19 - Veech RL, Kashiwaya Y, Gates DN, King MT, Clarke K. The energetics of ion distribution: the origin of the resting eletric potential of cells. IUBMB Life 2002; 54: 241-52.

20 - Garcia EAC. Biofísica. São Paulo: Sarvier; 1998.

21 - Cheng K, HaspeL HC, Vallano ML, Osotimehin B, Sonenberg $M$. Measurement of membrane potentials ( $p s i)$ of erythrocytes and withe adipocytes by the accumulation of triphenyImethylphosphonium cation. J Membr Biol 1980; 56: 191-201.

22 - Malaisse WJ, Herchuelz A, Sener A. Inorganic íons in insulin secretion. In: Cooperstein SJ, Watkins D. The islets of Langerhans. London: Academic Press;1981. p. 149-71.

23 - Bear MF, Connors, BW, Paradiso MA. Neurociências. Desvendando o sistema nervoso. Porto Alegre: Artmed; 2002.

24 - Legtenberg RJ, Houston RJF, Oeseburg B, Smits P. Physiological insulin concentrations protect against ischemia-induced loss of cardiac function in rats. Comp Biochem Physiol 2002; 132: 161-7.

Recebido em 02/05/2007

Aprovado em 25/06/2007 